\title{
Pengaruh Kepemimpinan Kepala Sekolah, Sikap Guru, Kompetensi Guru Terhadap Kinerja Guru di SMK Negeri 3 Pematangsiantar
}

\author{
Samsumantri \\ Prodi Magister Manajemen Pendidikan Tinggi, Universitas Muhammadiyah Sumatera Utara, Medan, Indonesia \\ Email: samsumantri007@gmail.com
}

\begin{abstract}
Abstrak-Penelitian ini bertujuan untuk menguji pengaruh Kepemimpinan kepala sekolah, Sikap guru, Kompetensi guru terhadap kinerja guru SMK Negeri 3 pematangsiantar baik secara parsial maupun simultan. Sampel pada penelitian ini adalah Guru SMK Negeri 3 pematangsiantar yang berjumlah 98 orang. Data dalam penelitian ini adalah data primer.Data dikumpulkan dengan menggunakan angket. Metode analisa yang digunakan adalah model Regresi Linear Berganda. Untuk menguji hipotesis secara simultan digunakan Uji F dan secara parsial digunakan Uji t. Hasil dari pengujian yang dilakukan dengan SPSS diperoleh persamaan regresi berganda: $\mathbf{Y}=\mathbf{1 0 , 8 5 7}+\mathbf{1 , 0 8 4} \mathbf{X}_{\mathbf{1}}+\mathbf{0 , 1 4 4} \mathbf{X}_{\mathbf{2}}+\mathbf{0 , 2 3 2} \mathbf{X}_{3}$,yang berarti nilai konstanta sebesar 10,857 yang menunjukkan bahwa apabila kepemimpinan kepala sekolah, sikap guru dan kompetensi guru diasumsikan bernilai nol, maka nilai dari kinerja guru adalah sebesar 10,857. Jika variabel bebas meningkat $1 \%$ maka kinerja guru akan meningkat. Hasil hipotesa uji thitung variabel penelitian adalah variabel kepemimpinan kepala sekolah diperoleh thitung 8,691 dengan probabilitas signifikan 0,000 lebih kecil dari tingkat keyakinan (level of significant) $\alpha=0,05$, variabel sikap guru diperoleh thitung 2,753 dengan probabilitas signifikan 0,007 lebih kecil dari tingkat keyakinan (level of significant) $\alpha=0,05$. Variable kompetensi guru diperoleh thitung3,807 dengan probabilitas signifikan 0,000 lebih kecil dari tingkat keyakinan (level of significant) $\alpha=0,05$. Maka keputusan yang diambil adalah menolak $\mathrm{H}_{0}$ dan menerima $\mathrm{H}_{\mathrm{a}}$, artinya kepemimpinan kepala sekolah, sikap guru,kompetensi guru berpengaruh positif dan signifikan terhadap kinerja guru SMK Negeri 3 pematangsiantar.
\end{abstract}

Kata Kunci: Kepemimpinan Kepala Sekolah; Sikap Guru; Kompetensi Guru; Kinerja Guru

\begin{abstract}
This study aims to examine the effect of principal leadership, teacher attitude, teacher competence on teacher performance at SMK Negeri 3 Pematangsiantar, either partially or simultaneously. The sample in this study were teachers of SMK Negeri 3 Pematangsiantar totaling 98 people. The data in this study are primary data. The data were collected using a questionnaire. The analytical method used is the Multiple Linear Regression model. To test the hypothesis simultaneously the F test is used and partially the $t$ test is used. The results of the tests carried out with SPSS obtained multiple regression equations: $Y=10.857+1.084$ X1 + $\mathbf{0 . 1 4 4}$ X2 + 0.232 X3, which means a constant value of 10.857 which indicates that if the principal's leadership, teacher attitudes and teacher competencies are assumed to be zero, then the value is zero. of the teacher's performance is equal to 10,857. If the independent variable increases by $1 \%$, the teacher's performance will increase. The results of the $\mathrm{t}$-test hypothesis of the research variable are the principal's leadership variable obtained tcount8,691 with a significant probability of 0.000 less than the level of confidence (level of significant $)=0.05$, the teacher's attitude variable is obtained tcount 2.753 with a significant probability of 0.007 smaller than the level of confidence (level of significant) $=0.05$. The teacher competency variable was obtained tcount 3.807 with a significant probability of 0.000 less than the level of confidence (level of significant) $=0.05$. So the decision taken is to reject $\mathrm{H} 0$ and accept Ha, meaning that the principal's leadership, teacher attitudes, teacher competence have a positive and significant effect on the performance of teachers at SMK Negeri 3 Pematangsiantar.
\end{abstract}

Keywords: Principal Leadership; Teacher Attitude; Teacher Competence; Teacher Performance

\section{PENDAHULUAN}

Kepala Sekolah merupakan seorang tenaga fungsional guru yang diberi tugas untuk memimpin suatu sekolah dimana diselenggarakan proses belajar mengajar atau tempat dimana terjadi interaksi antara guru yang memberi pelajaran dan murid yang menerima pelajaran. Dengan ini Kepala Sekolah bisa dikatakan sebagai pemimpin di satuan pendidikan yang tugasnya menjalankan menejemen satuan pendidikan yang dipimpin.

Kompetensi kepribadian merupakan unsur pembentuk karakter manusia. Kepribadian yang baik tentunya akan mencerminkan karakter yang baik. Pada implementasi di dalam dunia pendidikan, kompetensi kepribadian memiliki pengaruh yang besar terhadap perilaku yang ditunjukkan seorang guru (Isdiana, 2013). Perilaku yang menjadikan guru sebagai sosok nyata dalam memberikanteladan kepada siswanya. Seringkali disampaikan bahwa guru adalah sosok yang selayaknya dihormati dan diteladani dalam setiap perilaku dan tindakannya.

Pribadi yang dewasa, arif, dan berakhlak mulia tentunya tidak akan dapat diajarkan didalam buku teks semata. Hal tersebut adalah sikap yang dapat dipelajari melalui tindakan yang nyata (RAHMAN \& SUROTO, 2017). Oleh karena itu, pribadi yang ditunjukkan oleh para siswa adalah cerminan dari pembelajaran karakter yang disampaikan seorang guru melalui tingkah laku yang ditunjukkannya.

Kompetensi kepribadian guru akan memiliki pengaruh besar terhadap perkembangan karakter siswa sekolah menengah atas, sehingga guru harus memiliki pribadi yang kuat untuk menjadi teladan bagi para siswanya (Resawati \& Larashati, 2016). Hal ini akan bermanafaat untuk membentuk karakter yang positif dan membentengi diri siswa dari pengaruh negatif lingkungannya.

Guru digolongkan menjadi beberapa jenis, yaitu guru kelas, guru mata pelajaran serta guru bimbingan dan konseling. Guru kelas memiliki tugas, tanggungjawab, wewenang, dan hak secara penuh dalam proses pembelajaran, kecuali mata pelajaran jasmani dan agama (Sumarno, 2009). Selanjutnya, guru mata pelajaran, yaitu guru yang memiliki tugas, tanggung jawab, dan hak secara penuh dalam proses pembelajaran pada mata pelajaran tertentu sesuai 
dengan bidangnya. Lain halnya dengan guru bimbingan dan konseling, yaitu guru yang memiliki tugas, tanggung jawab, wewenang, dan hak secara penuh dalam kegiatan bimbingan dan konseling terhadap siswa. Apapun golongannya, guru harus dapat melakukan semua perannya dengan baik, sehingga diperoleh hasil yang baik bagi siswa ditinjau dari segi afektif, kognitif, dan pikomotor.

Hasil penilaian kinerja guru diharapkan dapat bermanfaat bagi penentuan kebijakan yang terkait dengan peningkatan mutu dan kinerja guru (Trisnawinata, Rosita, \& Pd, 2016). Penilaian kinerja guru merupakan acuan bagi sekolah untuk menetapkan pengembangan karir dan promosi guru. Lain halnya bagi guru, penilaian kinerja guru merupakan pedoman untuk mengetahui butir-butir tugas, sehingga dapat dijadikan sarana perbaikan kualitas kinerjanya.

SMK Negeri 3 Pematangsiantar merupakan Sekolah Menengah Kejuruan yang berdiri tahun 1974 dengan enam kompetensi keahlian, yaitu Tata Busana, Perhotelan, Kecantikan, Tata Boga, RPL dan TKJ. Sekolah ini dipimpin oleh kepala sekolah yang disiplin. Kedisiplinan tersebut dapat ditunjukkan melalui ketepatan waktu masuk jam kerja dan keberadaan kepala sekolah saat kegiatan belajar mengajar masih berlangsung (Widyansari, 2014).

Berdasarkan wawancara dengan dua siswa kelas XII SMK Negeri 3 Pematangsiantar pada bulan Januari 2020, metode dan media pembelajaran yang digunakan guru SMK Negeri 3 Pematangsiantar dianggap kurang variatif. Metode pembelajaran yang digunakan hanya terbatas pada metode ceramah dan media pembelajaran yang digunakan terlalu mengandalkan modul. Oleh sebab itu, proses pembelajaran kurang menarik. Metode dan media pembelajaran yang kurang menarik telah membuat siswa merasa bosan. Realita ini menunjukkan bahwa kemampuan guru dalam menjalankan profesinya masih kurang.

\section{KERANGKA TEORI}

\subsection{Pengaruh Kepemimpinan Kepala Sekolah terhadap Kinerja Guru}

Arif Tri Handoko (2015) "Pengaruh Kepemimpinan Kepala Sekolah Terhadap Kinerja Guru SD Negeri Dabin IV Kecamatan Watukumpul Kabupaten Pemalang" (Handoko, 2015). Penelitian ini bertujuan untuk mengetahui pengaruh Kepemimpinan Kepala Sekolah terhadap kinerja guru SD Negeri Dabin IV Kecamatan Watukumpul Kabupaten Pemalang. Hasil penelitian ini menunjukkan bahwa kepemimpinan kepala sekolah memiliki pengaruh positif terhadap kinerja guru.

\subsection{Pengaruh Sikap Guru Terhadap Kinerja Guru}

Romi Rachman Hakim (2020) tentang "Pengaruh Sikap Kerja Terhadap Kinerja Guru Tidak Tetap Di SMK Insan Mandiri Kabupaten Bandung Barat" (Hakim, 2020). Hasil penelitian menunjukan bahwa sikap kerja memiliki pengaruh yang positif dan signifikan terhadap kinerja guru di SMK Insan Mandiri Kabupaten Bandung Barat.

\subsection{Pengaruh Kompetensi Guru Terhadap Kinerja guru}

Mufidah, Silvia L, Manday, Lisbeth Menaneke (2014) tentang "Analisis tingkat pendidikan, kompetensi, dan kompensasi terhadap kinerja karyawan pada PT. Asuransi Jasa Raharja Putra Manado" (Mananeke, Mandey, \& Mufidah, 2014). Hasil penelitian menunjukkan bahwa tingkat pendidikan, kompetensi, dan kompensasi secara simultan berpengaruh terhadap kinerja. Adapun hasil penelitian lain Sudarmin Manik, Nona Syafina (2018) tentang "pengaruh Kompetensi Terhadap Kinerja Dosen Sekolah Tinggi Ilmu Ekonomi Riau" (Sari, Wardi, \& Evanita, 2015). Hasil penelitian menunjukkan bahwa kompetensi berpengaruh positif dan signifikan terhadap kinerja dosen.

\section{METODOLOGI PENELITIAN}

\subsection{Desain Penelitian}

Berdasarkan latar belakang dan rumusan masalah dalam penelitian ini, maka penelitian ini dengan pendekatan kuantitatif, dimana dalam penelitian ini semua data disajikan dalam angka, mulai dari pengumpulan data, menganalisis data serta penyajian dari hasil penelitian. Penelitian ini merupakan penelitian jenis ex-post facto karena penelitian ini mengungkapkan data atau kejadian yang ada tanpa mengubah atau memanipulasi variabel maupun sampel yang diteliti. Penelitian ex-post facto dilakukan untuk meneliti peristiwa yang telah terjadi. Penelitian ini bermaksudmengungkappengaruhantara variabel bebas yaitu kepemimpinan kepala sekolah, sikap guru, kinerja guru terhadap kompetensiguru.

\subsection{Populasi Dan Sampel}

\section{a. Populasi}

Populasi adalah wilayah generalisasi yang terdiri atas objek/subjek yang mempunyai kualitas dan karakteristik tertentu yang di tetapkan oleh peneliti untuk dipelajari dan kemudian diambil kesimpulanntya. Jadi pupulasi bukan hanya orang tetapi juga objek dan benda-benda alam yang lain. Populasi juga bukan bukan sekedar jumlah yang ada pada objek/subjek yang dipelajari tetapi meliputi seluruh karakteristik sifat yang dimiliki oleh subjek atau objek itu. Sugiyono (2017:90). 


\section{b. Sampel}

Sampel adalah bagian dari jumlah dan karakteristik yang dimiliki oleh populasi tersebut. Menurut (Arikunto, 2013) bahwa apabila subjeknya kurang dari 100 lebih baik diambil semua sehingga penelitian ini merupakan penelitian populasi. Jika subjeknya besar dapat diambil untuk $10-15 \%$ atau $20-25 \%$ atau lebih.

Dalam penelitian ini metode yang digunakan dalam penarikan sampel adalah total sampling yaitu teknik pengambilan sampel dimana jumlah sampel sama dengan populasi. Jumlah populasi penelitian ini berjumlah 98 . Sedangkan untuk sampelnya berjumlah 98 orang responden.

\subsection{Instrumen Penelitian}

Instrumen penelitian merupakan alat ukur yang menghasilkan informassi dalam melakukan penelitian. Instruemen yang digunkan dalam penelitian ini yaitu angket/kuesioner. Angket atau kuesioner tersebut berisi pernyataan-pernyataan yang akan diajukan kepada guru SMK Negeri 3 Pematangsiantar untuk memperolah informasi mengenai variabel kepemimpinan kepala sekolah, sikap guru, kinerja guru terhadap kompetensi guru.

Penskoran yang digunakan dalam instrumen yaitu dengan menggunkan skala likert. Skala likert digunakan untuk penelitian ini berdimensi 5 dengan rentang nilai 1 sampai 5 yang dapat dilihat pada tabel 2 sebagai berikut:

Tabel 1. Skor Skala Likert

\begin{tabular}{lcc}
\hline \multicolumn{1}{c}{ Alternatif jawaban } & Pernyataan positif & Pernyataan negatif \\
\hline Sangat Setuju (SS) & 5 & 1 \\
Setuju (S) & 4 & 2 \\
Kurang Setuju (KS) & 3 & 3 \\
Tidak Setuju (TS) & 2 & 4 \\
Sangat Tidak Setuju (STS) & 1 & 5 \\
\hline
\end{tabular}

Berikut merupakan kisi-kisi instrumen dari masing-masing variabel:

Tabel 2. Kisi-Kisi Instrumen

\begin{tabular}{|c|c|c|c|c|}
\hline No & Variabel & Indikator & Nomor butir & Jumlah \\
\hline \multirow[t]{6}{*}{1} & Kepemimpinan & Kepribadian & 1 & \multirow{6}{*}{9} \\
\hline & Kepala Sekolah & $\begin{array}{l}\text { Pengetahuan terhadap tenaga } \\
\text { kependidikan }\end{array}$ & 2,3 & \\
\hline & & Visi dan misi sekolah & 4 & \\
\hline & & Kemampuan mengambil & 5,6 & \\
\hline & & keputusan & 7 & \\
\hline & & Kemampuan Berkomunikasi & 8,9 & \\
\hline \multirow[t]{3}{*}{2} & Sikap Guru & Kepedulian & $1,2,3,4,5$ & \multirow{3}{*}{18} \\
\hline & & Tanggung Jawab & $12,14,15,16,17$, & \\
\hline & & Antusias & 18 & \\
\hline \multirow[t]{4}{*}{3} & Kompetensi Guru & Pedagogik & $1,2,3,4,5,6$ & \multirow{4}{*}{19} \\
\hline & & Kepribadian & $7,8,9,10,11$ & \\
\hline & & Sosial & $12,13,14$ & \\
\hline & & Profesional & $15,16,17,18,19$ & \\
\hline \multirow[t]{3}{*}{4} & Kinerja Guru & Perencanaan Pembelajaran & $1,2,3,4$ & \multirow{3}{*}{16} \\
\hline & & Pelaksanaan Pembelajaran & $\begin{array}{l}5,6,7,8,9 \\
10,11,12\end{array}$ & \\
\hline & & Evaluasi Pembelajaran & $13,14,15,16$ & \\
\hline
\end{tabular}

\subsection{Analisis Regresi Linear Berganda}

Peneliti menggunakan analisi regresi linear berganda untuk mengetahui pengaruh variabel bebas terhadap variabel terikat. Peneliti menggunakan bantuan SPSS agar hasil yang diperoleh lebih terarah. Persamaan regresi berganda yang digunakan adalah:

$$
\begin{array}{cl}
\hat{Y}=\mathrm{a}+\mathrm{b}_{1} \mathrm{X}_{1}+\mathrm{b}_{2} \mathrm{X}_{2}+\mathrm{e} & \text { (Sudjana, 2016:348) } \\
\text { Dimana: } & =\text { Kinerja Guru } \\
\mathrm{Y} & =\text { kepemimpinan kepala sekolah } \\
\mathrm{X}_{1} & =\text { sikap guru } \\
\mathrm{X}_{2} & =\text { kompetensi guru } \\
\mathrm{X}_{3} & =\text { Konstanta } \\
\mathrm{a} &
\end{array}
$$




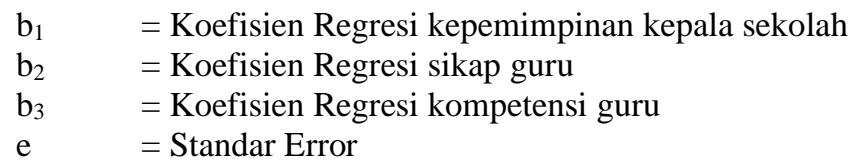

Fungsi dari analisis regresi ini untuk mengetahui apakah ada pengaruh variabel bebas $\left(\mathrm{X}_{1}\right)$ dan variabel bebas $\left(\mathrm{X}_{2}\right)$ terhadap variabel terikat $(\mathrm{Y})$ dalam hal ini yaitu

\subsection{Hipotesis Penelitian}

Berdasarkan batasan, rumusan masalah dan kerangka konseptual yang telah dikemukakan sebelumnya, maka hipotesis penelitian ini adalah:

1. Terdapat pengaruh antara Kepemimpinan Kepala Sekolah terhadap Kinerja Guru SMK Negeri 3 Pematangsiantar.

2. Terdapat pengaruh antara Sikap Guru terhadap kinerja guru SMK Negeri 3 Pematangsiantar.

3. Terdapat pengaruh antara Kompetensi Guru terhadap Kinerja Guru SMK Negeri 3 Pematangsiantar.

Terdapat pengaruh positif dan signifikan antara Kepemimpinan kepala sekolah,Sikap guru dan kompetensi guru secara bersama-sama dengan kinerja guru SMK Negeri 3 Pematangsiantar.

\section{HASIL DAN PEMBAHASAN}

\subsection{Analisa Data}

\section{a. Uji Validitas}

Teknik untuk mengukur validitas kuesioner adalah ssebagai berikut dengan menghitung korelasi antar data pada masing-masing pernyataan dengan skor total. Item Instrumen dianggap valid jika lebih besar dari 0,3 atau bisa juga dengan membandingkannya dengan $r_{\text {kritis. }}$ Jika $r_{\text {hitung }}>r_{\text {kritis }}$ maka valid. Adapun hasil uji validitas dalam penelitian ini.

Tabel 3. Hasil Uji Validitas

\begin{tabular}{|c|c|c|c|c|}
\hline Variabel & Butir Instrumen & $r_{\text {hitung }}$ & $\mathrm{r}_{\text {kritis }}$ & Keterangan \\
\hline \multicolumn{5}{|l|}{ Kepemimpinan } \\
\hline \multirow{9}{*}{ kepala sekolah } & $\mathrm{X} 1.1$ & 0,544 & 0,3 & Valid \\
\hline & $\mathrm{X} 1.2$ & 0,390 & 0,3 & Valid \\
\hline & $\mathrm{X} 1.3$ & 0,412 & 0,3 & Valid \\
\hline & $\mathrm{X} 1.4$ & 0,521 & 0,3 & Valid \\
\hline & $\mathrm{X} 1.5$ & 0,610 & 0,3 & Valid \\
\hline & X1.6 & 0,537 & 0,3 & Valid \\
\hline & $\mathrm{X} 1.7$ & 0,686 & 0,3 & Valid \\
\hline & $\mathrm{X} 1.8$ & 0,654 & 0,3 & Valid \\
\hline & $\mathrm{X} 1.9$ & 0,498 & 0,3 & Valid \\
\hline \multirow[t]{18}{*}{ Sikap Guru } & $\mathrm{X} 2.1$ & 0,517 & 0,3 & Valid \\
\hline & $\mathrm{X} 2.2$ & 0,697 & 0,3 & Valid \\
\hline & $\mathrm{X} 2.3$ & 0,517 & 0,3 & Valid \\
\hline & $\mathrm{X} 2.4$ & 0,706 & 0,3 & Valid \\
\hline & $\mathrm{X} 2.5$ & 0,584 & 0,3 & Valid \\
\hline & X2.6 & 0,517 & 0,3 & Valid \\
\hline & $\mathrm{X} 2.7$ & 0,687 & 0,3 & Valid \\
\hline & $\mathrm{X} 2.8$ & 0,697 & 0,3 & Valid \\
\hline & $\mathrm{X} 2.9$ & 0,468 & 0,3 & Valid \\
\hline & $\mathrm{X} 2.10$ & 0,687 & 0,3 & Valid \\
\hline & $\mathrm{X} 2.11$ & 0,361 & 0,3 & Valid \\
\hline & $\mathrm{X} 2.12$ & 0,584 & 0,3 & Valid \\
\hline & $\mathrm{X} 2.13$ & 0,558 & 0,3 & Valid \\
\hline & $\mathrm{X} 2.14$ & 0,706 & 0,3 & Valid \\
\hline & $\mathrm{X} 2.15$ & 0,706 & 0,3 & Valid \\
\hline & $\mathrm{X} 2.16$ & 0,697 & 0,3 & Valid \\
\hline & $\mathrm{X} 2.17$ & 0,517 & 0,3 & Valid \\
\hline & $\mathrm{X} 2.18$ & 0,433 & 0,3 & Valid \\
\hline \multirow[t]{6}{*}{ Kompetensi Guru } & X3.1 & 0,839 & 0,3 & Valid \\
\hline & X3.2 & 0,449 & 0,3 & Valid \\
\hline & X3.3 & 0,626 & 0,3 & Valid \\
\hline & X3.4 & 0,718 & 0,3 & Valid \\
\hline & X3.5 & 0,656 & 0,3 & Valid \\
\hline & X3.6 & 0,867 & 0,3 & Valid \\
\hline
\end{tabular}




\begin{tabular}{|c|c|c|c|c|}
\hline Variabel & Butir Instrumen & $r_{\text {hitung }}$ & $\mathrm{r}_{\text {kritis }}$ & Keterangan \\
\hline \multirow{29}{*}{ Kinerja Guru } & X3.7 & 0,718 & 0,3 & Valid \\
\hline & X3.8 & 0,867 & 0,3 & Valid \\
\hline & X3.9 & 0,552 & 0,3 & Valid \\
\hline & X3.10 & 0,656 & 0,3 & Valid \\
\hline & X3.11 & 0,867 & 0,3 & Valid \\
\hline & X3.12 & 0,839 & 0,3 & Valid \\
\hline & X3.13 & 0,777 & 0,3 & Valid \\
\hline & X3.14 & 0,777 & 0,3 & Valid \\
\hline & X3.15 & 0,626 & 0,3 & Valid \\
\hline & X3.16 & 0,556 & 0,3 & Valid \\
\hline & Y1 & 0,786 & 0,3 & Valid \\
\hline & Y2 & 0,786 & 0,3 & Valid \\
\hline & Y3 & 0,805 & 0,3 & Valid \\
\hline & Y4 & 0,815 & 0,3 & Valid \\
\hline & Y5 & 0,786 & 0,3 & Valid \\
\hline & Y6 & 0,815 & 0,3 & Valid \\
\hline & Y7 & 0,786 & 0,3 & Valid \\
\hline & Y8 & 0,803 & 0,3 & Valid \\
\hline & Y9 & 0,786 & 0,3 & Valid \\
\hline & Y10 & 0,805 & 0,3 & Valid \\
\hline & Y11 & 0,803 & 0,3 & Valid \\
\hline & Y12 & 0,805 & 0,3 & Valid \\
\hline & Y13 & 0,815 & 0,3 & Valid \\
\hline & Y14 & 0,786 & 0,3 & Valid \\
\hline & Y15 & 0,654 & 0,3 & Valid \\
\hline & Y16 & 0,786 & 0,3 & Valid \\
\hline & Y17 & 0,786 & 0,3 & Valid \\
\hline & Y18 & 0,805 & 0,3 & Valid \\
\hline & Y19 & 0,815 & 0,3 & Valid \\
\hline
\end{tabular}

\section{b. Uji Reliabilitas}

Uji reliabilitas adalah metode pengujian yang digunakan untuk menetapkan apakah instrument yang dalam hal ini adalah kuesioner dapat digunakan lebih dari satu kali, paling tidak boleh responden yang sama akan menghasilkan data yang konsisten dan teknik yang digunakan menghitung menggunakan bantuan SPSS (Statistical Product and Servise Solutions) Versi 21. Dengan kata lain, reliabilitas dikatakan variabel ika memberikan nilai >0,60.

Tabel 4. Uji Reliabilitas Variabel Kepemimpinan Kepala Sekolah $\left(\mathrm{X}_{1}\right)$

\begin{tabular}{ccc}
\hline Cronbach's Alpha & N of Item & Hasil Uji \\
\hline 0,727 & 9 & Reliabel \\
\hline
\end{tabular}

Tabel 5. Uji Reliabilitas Variabel sikap guru $\left(\mathrm{X}_{2}\right)$

\begin{tabular}{ccc}
\hline Cronbach's Alpha & N of Item & Hasil Uji \\
\hline 0,748 & 18 & Reliabel \\
\hline \multicolumn{3}{c}{ Tabel 6. Uji Reliabilitas Variabel kompetensi guru $\left(\mathrm{X}_{3}\right)$} \\
\hline Cronbach's Alpha & N of Item & Hasil Uji \\
\hline 0,764 & 16 & Reliabel \\
\hline \multicolumn{3}{c}{ Tabel 7. Uji Reliabilitas Variabel Kinerja Guru (Y) } \\
\hline Cronbach's Alpha & Nof Item & Hasil Uji \\
\hline 0,767 & 19 & Reliabel \\
\hline
\end{tabular}

\subsection{Uji Asumsi Klasik}

\section{a. Uji Normalitas}

Uji normalitas dengan menggunakan uji one-sample Kolmogrov-Smirnov, hal ini untuk memeriksa apakah populasi berdistribusi normal atau tidak. Uji normalitas perlu dicek keberlakuannya agar langkah-langkah selannjutnya dapat dipertanggungjawabkan. Data dikatakan berdistribusi normal apabila nilai Asymp. Sig. (2-tailed) dari masing-masing variabel bernilai >0,05. maka teknik yang digunakan menggunakan SPSS Versi 21 
Tabel 8. Uji Normalitas

\begin{tabular}{cccccc}
\hline & \multicolumn{2}{c}{ One-Sample Kolmogorov-Smirnov Test } & & \\
& & $\mathrm{X} 1$ & $\mathrm{X} 2$ & $\mathrm{X} 3$ & $\mathrm{Y}$ \\
\hline \multirow{3}{*}{ Normal Parameters ${ }^{\mathrm{a}, \mathrm{b}}$} & & 98 & 98 & 98 & 98 \\
& Mean & 37,12 & 75,41 & 68,58 & 77,83 \\
& Std. Deviation & 2,680 & 6,358 & 5,274 & 4,941 \\
\multirow{2}{*}{ Most Extreme Differences } & Absolute &, 113 &, 097 &, 119 &, 116 \\
& Positive &, 111 &, 097 &, 093 &, 116 \\
& Negative &,- 113 &,- 071 &,- 119 &,- 111 \\
Kolmogorov-Smirnov Z & 1,120 &, 960 & 1,179 & 1,146 \\
Asymp. Sig. (2-tailed) &, 162 &, 315 &, 124 &, 145 \\
\hline
\end{tabular}

a. Test distribution is Normal.

b. Calculated from data.

b. Uji Multikolinieritas

Multikolinieritas adalah kondisi terdapat hubungan linier atau korelasi yang tinggi antara masing-masing variabel independen dalam model regresi. Multikolinieritas biasanya terjadi ketika sebagian besar variabel yang digunakan saling terkait dalam suatu model regresi. Oleh karena itu masalah multikoliniearitas tidak terjadi pada regresi linier sederhana yang hanya melibatkan satu variabel independen.

Tabel 9. Uji Multikolinieritas

\begin{tabular}{|c|c|c|c|c|c|c|}
\hline \multirow{2}{*}{\multicolumn{2}{|c|}{ Model }} & \multirow{3}{*}{$\begin{array}{l}\text { Correlations } \\
\text { Zero-order }\end{array}$} & \multirow{3}{*}{ Partial } & \multirow{3}{*}{ Part } & \multicolumn{2}{|c|}{ Collinearity Statistics } \\
\hline & & & & & Tolerance & VIF \\
\hline \multirow{4}{*}{1} & (Constant) & & & & & \\
\hline & $\mathrm{X} 1$ & ,758 & ,668 & ,512 & ,760 & 1,316 \\
\hline & $\mathrm{X} 2$ &, 525 & ,273 &, 162 & ,772 & 1,296 \\
\hline & $\mathrm{X} 3$ &, 527 & ,366 & ,224 & ,822 & 1,216 \\
\hline
\end{tabular}

\section{c. Uji Parsial (Uji t)}

Uji t adalah uji yang dilakukan untuk mengetahui apakah antara variabel bebas yaitu kepemimpinan kepala sekolah, sikap guru dan kompetensi guru, dan variabel terikat yaitu kinerja guru mempunyai hubungan yang signifikan atau tidak. Untuk mengetahui $\mathrm{t}_{\text {tabel }}$ digunakan ketentuan $\mathrm{df}=\mathrm{n}-\mathrm{k}-1$ pada level kesalahan $5 \%$ atau 0,05 dengan tingkat keyakinan $95 \%$ atau 0,95 .

\section{d. Uji Simultan (Uji F)}

Untuk menguji signifikansi hubungan variabel bebas dengan variabel terikat secara simultan, maka digunakan Uji F. Nilai F digunakan untuk menguji ketepatan model atau goodness of fit, apakah model persamaan yang terbentuk masuk dalam kriteria cocok (fit) atau tidak. Perhitungan dibantu dengan menggunakan bantuan SPSS Versi 21. Jika Asymp. Sig.(2-tailed) < 0.05 maka secara simultan keseluruhan variabel indenpenden memiliki pengaruh secara bersama-sama pada tingkat signifikan $5 \%$.

Tabel 10. Hasil Uji F

\begin{tabular}{|c|c|c|c|c|c|c|}
\hline \multicolumn{6}{|c|}{ ANOVA $^{\mathrm{a}}$} & Sig. \\
\hline & Regression & 1594,426 & 3 & 531,475 & 64,577 &, $000^{\mathrm{b}}$ \\
\hline 1 & Residual & 773,625 & 94 & 8,230 & & \\
\hline & Total & 2368,051 & 97 & & & \\
\hline
\end{tabular}

a. Dependent Variable: Y

b. Predictors: (Constant), X3, X2, X1

\section{e. Regresi linier berganda}

Penelitian ini memiliki tujuan untuk menganalisa pengaruh kepemimpinan kepala sekolah $\left(\mathrm{X}_{1}\right)$, sikap guru $\left(\mathrm{X}_{2}\right)$ dan kompetensi guru $\left(\mathrm{X}_{3}\right)$ terhadap kinerja guru $(\mathrm{Y})$. Analisa data dalam penelitian ini menggunakan analisa regresi linear berganda. Analisa regresi linear berganda digunakan untuk mengetahui pengaruh variabel bebas (X) dan variabel terikat Y, dimana variabel $\mathrm{X}$ adalah kepemimpinan kepala sekolah, sikap guru, kompetensi guru dan variabel Y adalah kinerja guru. 
Tabel 11. Regresi Linier Berganda

\begin{tabular}{|c|c|c|c|c|c|c|}
\hline \multicolumn{2}{|c|}{$\begin{array}{l}\text { Coefficients }^{\mathbf{a}} \\
\text { Model }\end{array}$} & \multicolumn{2}{|c|}{ Unstandardized Coefficients } & \multirow{2}{*}{$\begin{array}{l}\text { Standardized } \\
\text { Coefficients } \\
\text { Beta }\end{array}$} & \multirow{2}{*}{$\mathrm{t}$} & \multirow{2}{*}{ Sig. } \\
\hline & & B & Std. Error & & & \\
\hline \multirow{4}{*}{1} & (Constant) & 10,857 & 4,941 & & 2,197 & ,030 \\
\hline & X1 & 1,084 &, 125 & ,588 & 8,691 & 000 \\
\hline & $\mathrm{X} 2$ &, 144 &, 052 &, 185 & 2,753 & ,007 \\
\hline & X3 & ,232 & ,061 & ,248 & 3,807 & ,000 \\
\hline
\end{tabular}

Berdasarkan hasil pengolahan data pada tabel 4.10 di atas, diperoleh model persamaan $\mathbf{Y}=\mathbf{1 0 , 8 5 7}+\mathbf{1 , 0 8 4 X _ { 1 }}+$ $\mathbf{0 , 1 4 4 X _ { 2 }}+\mathbf{0 , 2 3 2 X}$, diartikan terdapat pengaruh positif antara variabel kepemimpinan kepala sekolah $\left(\mathrm{X}_{1}\right)$, sikap guru $\left(\mathrm{X}_{2}\right)$, dan kompetensi guru $\left(\mathrm{X}_{3}\right)$ terhadap variabel kinerja guru $(\mathrm{Y})$ pada SMK Negeri 3 Pematangsiantar.

\section{KESIMPULAN}

Berdasarkan hasil penelitian dan pembahasan yang telah dikemukan sebelumnya, maka dapat diambil kesimpulan bahwa kepemimpinan Kepala sekolah berpengaruh terhadap kinerja Guru SMK Negeri 3 Pematangsiantar. Hal ini berarti bahwa kepemimpinan kepala sekolah memiliki peranan penting untuk menunjang dan meningkatkan kinerja guru. Sikap Guru berpengaruh terhadap kinerja Guru SMK Negeri 3 Pematangsiantar. Hal ini menunjukkan bahwa dengan adanya sikap guru yang baik akan meningkatkan kinerja guru dalam menjalankan tugas dan kewajibannya sebagai guru Kompetensi Guru berpengaruh terhadap kinerja guru SMK Negeri 3 Pematangsiantar. Hal ini menunjukkan bahwa dengan Kompetensi Guru yang tinggi akan meningkatkan kinerja guru dalam menjalankan tugas dan kewajibannya sebagai guru. Kepemimpinan Kepala Sekolah, Sikap Guru, Kompetensi Guru secara bersama-sama berpengaruh terhadap kinerja guru SMK Negeri 3 Pematangsiantar. Hal ini menunjukkan bahwa dengan adanya Kepemimpinan Kepala Sekolah, Sikap Guru, Kompetensi Guru yang tinggi akan meningkatkan kinerja guru.

\section{DAFTAR PUSTAKA}

Hakim, R. R. (2020). Romi rachman hakim,2020.

Handoko, A. T. (2015). Pengaruh Kepemimpinan Kepala Sekolah Terhadap Kinerja Guru Sd Negeri Dabin Iv Kecamatan Watukumpul. Manejemen Pendidikan, 02, 4.

Isdiana. (2013). Pengaruh Kepemimpinan Kepala Sekolah dan Profesionalisme Guru terhadap Kinerja Guru SMP Negeri di Kecamatan Batang. Jurnal Penelitian IKIP PGRI Semarang.

Mananeke, L., Mandey, S., \& Mufidah, M. (2014). Analisis Tingkat Pendidikan, Kompetensi Dan Kompensasi Terhadap Kinerja Karyawan Pada Pt. Asuransi Jasaraharja Putera Manado. Jurnal Riset Ekonomi, Manajemen, Bisnis Dan Akuntansi, 2(2), 1339-1348. https://doi.org/10.35794/emba.v2i2.4726

RAHMAN, F., \& SUROTO, B. (2017). Model Pengembangan Kinerja Dosen Swasta (Studi pada Karyawan yang berprofesi sebagai Dosen). Human Sustainability Procedia.

Resawati, R., \& Larashati, I. (2016). Pengaruh Kepemimpinan Kepala Sekolah, Kompetensi Guru dan Kompensasi Terhadap Kinerja Guru. Jurnal Ekonomi, Bisnis \& Entrepreneurship, 4(2), 132-148.

Sari, P. I., Wardi, Y., \& Evanita, S. (2015). Pengaruh Kepemimpinan Kepala Sekolah Dan Kompetensi Guru Terhadap Kinerja Guru Bidang Produktifjurusan Manajemen Bisnis Di Smkkota Jambi. Dikadaya, 5(1), 80-93.

Sumarno. (2009). Pengaruh Kepemimpinan Kepala Sekolah dan Profesionalisme Guru Terhadap Kinerja Guru Sekolah Dasar Negeri di Kecamatan Paguyangan Kabupaten Brebes. 1-79.

Trisnawinata, L., Rosita, D. A., \& Pd, M. (2016). GURU TERHADAP KOMPETENSI PROFESIONAL GURU DI SMA PGRI LAWANG KABUPATEN MALANG TAHUN AKADEMIK 2015 / 2016. (20), 1-10.

Widyansari, F. (2014). Modal Sosial Dalam Pendidikan Berkualitas Di Sekolah Dasar Muhammadiyyah Muitihan. Modal Sosial Dalam Pendidikan Berkualitas Di Sekolah Dasar Muhammadiyyah Muitihan, (September). 